\title{
Use of criteria for appointment of land use planning commissioners
}

\author{
ALLEN J. SCHUH \\ Department of Management Sciences, School of Business and Economics \\ California State University, Hayward, California 94542
}

\begin{abstract}
Experiments were conducted to determine whether group discussion of criteria, political or technical emphasis in decision making, and the use of other judges' opinions would result in differential selection of candidates for three openings on a city's land use planning commission. Results indicated that there was a significant difference in how the planning commissioners were selected when the judges $(\mathrm{N}=244)$ made their selections after reviewing criteria and emphasizing either the political or technical aspects of their decision. The top six candidates were the same regardless of the manipulation, but the top three candidates changed after manipulation of experimental procedures. The criteria did not change in perceived relative importance as a result of discussion before or after selecting the planning commissioners $(N=295)$. There was no significant difference in how participants $(N=78)$ evaluated candidates, regardless of whether they were supplied with information on how other participants judged the same candidates.
\end{abstract}

In my community many appointive positions remained vacant years ago because qualified citizens would not assume the time-consuming volunteer positions that contribute so much to community life. As part of a mobile population, managers and professionals avoided commitment to their communities. It seemed that only the activists made their presence known, especially in nonpartisan appointments. However, as managers and professionals established roots, it became apparent that their leisure time could be put to productive use in community projects, such as youth sports, suicide prevention centers, transportation for the aged and disabled, safe houses for battered family members, library advisory groups, and many other activities that are frequently initiated and run by volunteers, or that at least cannot run without volunteer assistance.

Because the troubled economy has produced a less mobile society, many suburban communities are confronted with the other side of the volunteer problem. There are now many more willing volunteers than can possibly be used efficiently, especially in high-visibility positions, such as on the city council and land use planning commission. Recently in my community, there were 15 applicants for three openings on the land use planning commission, an unheard-of selection ratio even 5 years ago. Obviously, when appointments are made, candidates are going to receive far greater scrutiny than they would have in earlier years. If such appointments are to have credibility with the community, such scrutiny is essential and should pass inspection as having been a reasonable appointment, given the situation at the time. Passing such inspection on occasion gives credibility to appointments made at times when detailed analysis is not possible.
Perhaps if more frequent examination of the civic appointment process were undertaken, those who might consider participation for the first time would have the assurance that their merits alone would dictate their probability of being selected to serve.

This paper reports on several manipulations of the actual characteristics possible in the setting and how college-student participants in experiments reacted to those manipulations.

\section{METHOD}

\section{Participants}

Participants were 617 students enrolled in 12 sections of a course in organizational behavior. Participation in the experiment occurred at a time when community involvement was covered in the course.

Procedure

The first manipulation was to examine the effects of discussing selection criteria in small, four- to five-person groups, prior to the participants' individually evaluating the candidates. (The merits of group discussion have been covered thoroughly by Buys, 1978a, 1978b.) The list of criteria was the Community Leader Worksheet (Pfeiffer \& Jones, 1973) and is shown in Table 1. Sixteen characteristics are listed that might be used to describe a community leader. The task was to select from this list the five characteristics that were the most important. Participants were told to keep these criteria in mind for the candidate selection task. Participants $(\mathrm{N}=244)$ were divided into three groups: criteria-political, criteria-technical, and controlpolitical. Participants $(\mathrm{N}=72)$ who were in the criteria-political group received instructions that they should assume that they were members of the city council and that they should appoint people to the land use planning commission who would help them further their own political and financial interests. Participants $(N=87)$ who were in the criteria-technical group received instructions that they should assume that they were long-time residents of the city and that they should appoint people who 
Table 1

Criteria From the Community Leader Work Sheet in Final Rank Order
initiative
grasp of local issues
respect in community
generalized experience
awareness of local politics
interest in people
loyalty to community
good socializer
well organized
emotional stability
intelligence
financial independence
physical health and vigor
sense of humor
cultural interests
specialized experience

Table 2

Candidate Qualifications as Reported in the Local Newspaper

$A$ is a technical engineer at a research center about 8 miles away.

B is an attorney and former president of the Democratic club.

C is past president of the Junior Chamber of Commerce.

$D$ is active in the United Presbyterian Church.

E is vice-president of the County Taxpayers Association.

$F$ is president of the Chamber of Commerce and the Downtown Business Association. She owns a dress shop in the downtown area and recently led a merchant's fight with teenagers who stand on Main Street during the lunch hour.

G sits on the County Fair Board and was once a large developer in the city. He now develops in a city about 20 miles away. He still owns property interests in the city.

$\mathrm{H}$ is well known for community activities, is president of the local country club, and is owner of a financial consulting business in a town 35 miles away.

I is well known for community activities and belongs to one of the local homeowners' associations that is trying to downzone land in that neighborhood.

J works for a police department in research and development for a town about 25 miles away. He has sat on the city's citizen committee for budget review and traffic safety and currently serves on the County Social Services Commission.

$\mathrm{K}$ is a prominent Republican party worker.

$L$ is a college professor at a university about 15 miles away.

$M$ is a pharmacist in a town about 20 miles away.

$\mathrm{N}$ works for the Internal Revenue Service in a town 35 miles away.

$\mathrm{O}$ is a personnel manager of a paint company in a town about 20 miles away.

would contribute the most to a productive and satisfying community. Participants $(\mathrm{N}=85)$ in the control group received the political instructions but did not discuss criteria prior to decision making. The decision making task was to identify which 3 of the 15 candidates should be appointed to the land use planning commission. The candidates and their qualifications (Table 2) were listed in the same order as they were presented in the local newspaper. Candidates' names were replaced with the alphabetical designations $A$ to $\mathbf{O}$. A modification was made to the political and technical instructions for one candidate. Candidate $J$ had been described in the local newspaper as having been active in one city council member's campaign and as having managed another council member's campaign. This material was deleted when the instructions were changed to technical emphasis.
The second manipulation was a typical Delphi (Dalkey, Note 1) scenario that required a group of participants $(N=78)$ to evaluate the candidates without knowledge of how the other participants evaluated them. Participants were then given information on how all other decision makers rated the candidates, and a second vote was taken. The Delphi approach was the method used by the city council to make the actual appointments. Decision makers might clarify their position on some candidates based on what they perceive as general support in the larger group. As weak candidates are abandoned, some mediocre candidates on the first round may gain substantially and be compromise appointees.

The third manipulation $(\mathrm{N}=295)$ was to examine the effect of evaluating candidates and then considering the list of criteria for the position. It might be hypothesized that there would be a clearer perception of what good criteria are after seeing a group of representative candidates for the position. In a five-person group discussion, the experimental group $(\mathrm{N}=150)$ chose the five most important criteria to consider in making the appointments, after having reviewed the candidates and made their individual selection decision. The control condition $(N=145)$ examined and selected the criteria without seeing the lists of candidate qualifications.

\section{RESULTS}

The effect of discussing criteria prior to making the appointment decisions had a significant $\left(\chi^{2}=44.26\right.$, $\mathrm{C}=.39, \mathrm{p}<.001)$ effect on those decisions. There are real differences in decision making when there are criteria available for candidate evaluation. The change in rank of even the top six candidates was considerable. Individual chi-square tests were conducted for candidates across treatments to determine whether some candidates were affected more than others by the manipulations. Each manipulation produced a different three-person composition of the commission. (The only candidate, $\mathrm{H}$, who would have been selected by all three manipulations did not receive an actual appointment by the city council.) Candidate $\mathrm{C}$ was ranked lower $\left(\chi^{2}=8.87, \mathrm{C}=.18\right.$, $\mathrm{p}<.05)$ when criteria were present. Candidate $\mathrm{H}$ was ranked higher with the criteria present only on the political condition $\left(\chi^{2}=7.77, \mathrm{C}=.17, \mathrm{p}<.05\right)$. Candidate I was ranked higher only with criteria present under the technical condition $\left(\chi^{2}=22.04, \mathrm{C}=.28, \mathrm{p}<.001\right)$. The rank of candidates by experimental manipulation is shown in Table 3.

The second manipulation was done only for the political manipulation with criteria available to determine whether judges would change their decisions on candidate suitability based on how other judges had voted. The top six and bottom six positions were ranked the same for both the first and second ranking, and the only change was that Ranks 7 and 9 were transposed. Further analysis was dismissed. The opportunity to update a decision with knowledge of how others would rank applicants did not change the relative order of the only candidates who had a chance for the position.

The result of the third manipulation was that there was no significant effect on criteria importance when participants reviewed a representative group of candidates prior to evaluating the criteria. The Spearman's rho 
Table 3

Rank of Candidates by Experimental Manipulation

\begin{tabular}{cccc}
\hline & \multicolumn{3}{c}{ Manipulation } \\
\cline { 2 - 4 } Candidate & $\begin{array}{c}\text { Control- } \\
\text { Political }\end{array}$ & $\begin{array}{c}\text { Criteria- } \\
\text { Political }\end{array}$ & $\begin{array}{c}\text { Criteria- } \\
\text { Technical }\end{array}$ \\
\hline A & 8 & 8 & 8 \\
B & 5 & 4.5 & 6 \\
C & 9 & 10 & 10 \\
D & 14.5 & 12.5 & 12.5 \\
E & 7 & 7 & 7 \\
F & 3 & 4.5 & 2 \\
G & 4 & 3 & 5 \\
H & 2 & 1.5 & 3 \\
I & 6 & 6 & 1 \\
J & 1 & 1.5 & 4 \\
K & 10.5 & 10 & 12.5 \\
L & 10.5 & 14.5 & 9 \\
M & 12.5 & 12.5 & 12.5 \\
N & 14.5 & 14.5 & 12.5 \\
O & 12.5 & 10 & 15 \\
\hline
\end{tabular}

(Siegel, 1956) was $r_{s}=.959(p<.01)$ between ranks of criteria for experimental and control groups. Those who make appointments to nonpartisan offices operate with a stereotype that is probably close to the criteria considered in this study, probably because they personally have been very active in community activities for many years. All participants were of voting age and had probably exercised their franchise numerous times. Thus, it is likely that the manipulation gave them an opportunity to express the criteria they generally use in casting a ballot for public office, rather than opening up new considerations for their selection decision. Because the groups were not significantly different, the raw data were pooled and their rank order is shown in Table 1 .

\section{DISCUSSION}

Overall, the results indicated that participants had appointment criteria that were stable. They also had a stable perception of the type of person they wanted to hold a public service position in their community. They arrived at the same list of finalists and the same criteria regardless of manipulation. When they focused on criteria and political advancement, they arrived at almost the same decision that the city council reached in making its decision. When participants channeled their attention to technical competence, they revised the order of finalists but not who was included in the top six finalists. It might be that the influence of politics is far less than has been imagined. Each list of finalists included the same 6 of the 15 candidates. Only technical or political emphasis determined which three of the six were appointed. Probably, most readers would have thought that political influence would have played a greater role. What gives these results credibility is how close they were to the decision made by the city council (Candidates $F, G$, and $J$ were actually chosen).

With criteria before the decision makers, at least one of the top three candidates is different among the manipulations tested.
Thus, it is probably useful for those making the appointment decisions to consider a review of what characteristics of past appointees led to effectiveness in their service to the community. Perhaps a quick familiarization with these criteria could clarify the decision maker's intentions prior to appointment proceedings.

If these criteria were to be made available to prospective candidates, perhaps many of the less qualified candidates could save themselves the considerable effort of application and interviewing for the scarce openings, and they would know what they have to do to be eligible for serious consideration. Of the 15 candidates for the land use planning commission position, the top 6 were the only real contenders. The bottom six generally did not receive a single vote and could have put their time to use in other ways of service to their communities. The list of criteria is perhaps too general in some respects, but certainly, upwardly mobile citizens should give the criteria serious consideration if they wish to seek appointive positions. In statements of qualifications, candidates should indicate how they have demonstrated initiative, that they have knowledge of local issues, that they have gained respect in the community, that they have generalized experience, and that they have an awareness of local politics. Candidates should probably avoid reference to low-importance criteria, such as cultural interests, financial independence, physical health and vigor, a sense of humor, intelligence, and specialized experience. It is possible that an average applicant who could present a case for how the high-importance criteria apply to his background might do better than a more qualified applicant who does not address the high-importance issues.

A closer inspection of how the political process operates in local communities may add needed confidence in our system. What appeared to some to be a victory for political influence (the appointment of Candidate $\mathrm{J}$ ) could be seen in another light as a victory for the community (he was chosen using the criteria and was a finalist even under technical considerations). Selection decisions, at least in the exercise presented here, were made from top candidates by all manipulations. The political process only favored some of the top candidates more than other top candidates. In summary, when dealing with the top of the talent pool, it may not matter much from the community's viewpoint who gets the final appointment.

\section{REFERENCE NOTE}

1. Dalkey, N. C. The Delphi method: An experimental study of group opinion (Memorandum RM 5888-PR). Santa Monica, Calif: Rand Corporation, June 1969.

\section{REFERENCES}

BuYs, C. J. Humans would do better without groups. Personality and Social Psychology Bulletin, 1978, 4, 123-125. (a)

BuYs, C. J. On humans would do better without groups: A final note. Personality and Social Psychology Bulletin, 1978, 4, 568. (b)

Pfeiffer, J. W., \& Jones, J. E. Community leader worksheet: Exercise 115. In J. W. Pfeiffer \& J. E. Jones (Eds.), $A$ handbook of structured experiences for human relations training (Vol. 4). La Jolla, Calif: University Associates, 1973. Siegel, S. Nonparametric statistics for the behavioral sciences. New York: McGraw-Hill, 1956.

(Received for publication July 9, 1982.) 